\title{
BMJ Open Perspectives on the current state of Nigeria's emergency care system among participants of an emergency medicine symposium: a qualitative appraisal
}

\author{
Agnes Usoro (D) , ,2 Benjamin Aiwonodagbon (D) , ${ }^{3}$ Jonathan Strong (D) , \\ Sean Kivlehan (D) , ${ }^{4}$ Babatunde A Akodu (D) , ${ }^{5}$ Ayobami Olufadeji (D) ${ }^{6}$
}

To cite: Usoro A,

Aiwonodagbon B, Strong J, et al. Perspectives on the current state of Nigeria's emergency care system among participants of an emergency medicine symposium: a qualitative appraisal. BMJ Open 2021;11:e043869. doi:10.1136/ bmjopen-2020-043869

- Prepublication history and additional supplemental material for this paper are available online. To view these files, please visit the journal online. (http://dx.doi.org/10.1136/ bmjopen-2020-043869).

Received 25 August 2020 Accepted 05 May 2021
Check for updates

(C) Author(s) (or their employer(s)) 2021. Re-use permitted under CC BY-NC. No commercial re-use. See rights and permissions. Published by BMJ.

For numbered affiliations see end of article.

Correspondence to

Dr Agnes Usoro;

ausoro1@jhmi.edu

\section{ABSTRACT}

Introduction Emergency care systems provide timely and relevant care to the acutely ill and injured. Published commentaries have characterised deficiencies in the Nigerian emergency care system and offered potential solutions but have not included the perspectives of the Nigerian public. A more inclusive approach that includes feedback from the public may help improve the Nigerian emergency care system through better understanding of the needs, values and expectations of the community.

Methods Participants of an emergency medicine symposium participated in focus group discussions that were randomly divided into small groups led by two trained facilitators. These facilitators asked open-ended, semistructured questions to lead discussions in the English language. Participant responses were audio-recorded and transcribed verbatim into transcripts. Two independent investigators employed conventional content analysis to code the transcripts until thematic saturation was achieved.

Results Three descriptive themes emerged characterising the current state of Nigeria's emergency care system as it relates to prehospital care delivery, hospital care delivery and health system governance: rudimentary, vulnerable and disconnected. At the prehospital level, concepts revolved around emergency recognition and response, ambulance and frontline providers, and cultural norms. At the hospital level, concepts centred around the health workforce, clinical competency, hospital capacity and the burden of financial hardship. At the health system level, concepts concentrated on healthcare access and healthcare financing. Opportunities for emergency care system improvement at each component level were identified and explored.

Conclusions The participants in this study identified shortcomings and opportunities to improve prehospital care, hospital care and health system governance. The results of this study may help healthcare professionals, policy makers and community leaders identify gaps in the emergency care system and offer solutions in harmony with the needs, values and expectations of the community. If successful, these community-informed interventions may serve as a model to improve emergency care systems throughout Africa.
Strengths and limitations of this study

- This qualitative study elicits feedback from the Nigerian community regarding their emergency care needs.

- This study used a collaborative approach with local Nigerian research partners.

- While our findings are robust, they should be interpreted in the context of the focus group participants.

\section{INTRODUCTION}

On 28 May 2019, the Seventy-second World Health Assembly unanimously passed a resolution recognising the essential role emergency care systems play in preventing death and disability from acute illness and injury. ${ }^{1}$ Many low-and-middle income countries (LMICs) recognise the essential role of emergency care systems but are challenged in their pursuit of developing their emergency care system because they have traditionally prioritised resources on infectious diseases and maternal and child health. ${ }^{23}$ Universal health coverage, which ensures access to quality and effective health services without the burden of financial hardship, should be a priority objective for LMICs while developing their respective emergency care systems. ${ }^{4}$

Nigeria's health system has struggled to meet the needs of an ever-growing population despite economic advances that have increased the annual gross domestic product per capita from $\$ 568$ in 2000 to $\$ 2230$ in $2019 .{ }^{5}{ }^{6}$ When compared globally, Nigeria is ranked 142nd out of 195 countries when evaluating its performance on a comparative healthcare access and quality index. ${ }^{7}$ Further, Nigeria frequently loses its trained healthcare providers to other countries, suffering from one of the highest brain drains globally. ${ }^{8}$ Nigeria's ability to deliver accessible quality medical care is limited by its current 
healthcare infrastructure. Health facilities are poorly resourced and understaffed, especially in rural areas. ${ }^{9}$ Despite having the largest economy in Africa, Nigeria has 0.5 hospital beds per 1000 people, which falls below the average of 1.0 hospital bed per 1000 people in other subSaharan African countries. ${ }^{9} 10$ Moreover, there are only 47 tertiary hospitals-a mix of public, private and faithbased institutions-in the country with a population of over 200 million people. ${ }^{11}$

It is estimated that over half of all deaths in LMICs can be averted by effective emergency care delivery. ${ }^{12}$ In Nigeria, that would translate to approximately 1000000 lives saved every year, or 3000 lives every day. ${ }^{13} 14$ Like in most LMICs, Nigerian emergency departments are run by providers with little to no dedicated specialty training in emergency care as there are no recognised postgraduate training programmes in emergency medicine. ${ }^{1516} \mathrm{It}$ is estimated that, of the 1.6 million deaths recorded annually in Nigeria, $10 \%-15 \%$ occur in emergency departments. ${ }^{17}$ Lagos is one of the few states in Nigeria with a public ambulance transporting system, but many of these ambulances are non-functional. ${ }^{18}$ And for those that are, the ability of these ambulances to get to the scene is difficult with the current road traffic system. ${ }^{19}$ Commentaries published by healthcare professionals have characterised deficiencies in the Nigerian emergency care system and offered potential solutions. ${ }^{20-22}$ However, these commentaries have not included the perspectives of the Nigerian public. A more inclusive approach that includes feedback from the public may help policy makers improve the Nigerian emergency care system through better understanding of the needs, values and expectations of the community.

We sought to identify the public's perceptions of Nigeria's emergency care system at an emergency medicine symposium in Lagos, Nigeria, on 28 March 2020. Members of the local community-both health professionals and laypeople-gathered to share perspectives on strengthening the Nigerian emergency care system and ultimately saving lives. We facilitated discussions with symposium participants to better understand their impression of Nigeria's emergency care system-including the current state of healthcare delivery, challenges to seeking and providing timely emergency care, and opportunities for improving on the emergency care system so that it meets the needs of the populace.

\section{METHODS}

\section{Study design}

Focus groups are recognised as ideal avenues for investigating complex and unique concepts, particularly when they are dependent on obscure factors or determinants. ${ }^{23}{ }^{24}$ We invited participants in an emergency medicine symposium-an ideal setting to gather members of the public with insight and interest-to participate in focus group discussions centred on perceptions of the emergency care system in Nigeria. The symposium was
Table 1 Demographic data of discussion group participants

\begin{tabular}{llcc}
\hline & & $\begin{array}{l}\text { Number of } \\
\text { participants } \\
\text { (n=66) }\end{array}$ & Percentage \\
\hline \multirow{2}{*}{ Sex } & Male & 33 & 50.0 \\
\multirow{2}{*}{ Occupation } & Female & 33 & 50.0 \\
& Physician & 29 & 43.9 \\
& Nurse & 3 & 4.5 \\
& Medic & 19 & 28.8 \\
& Medical student & 1 & 1.5 \\
& Non-healthcare & 14 & 21.2 \\
& professionals & & \\
\hline
\end{tabular}

hosted by WeBelieve Health, a non-profit organisation, in Lagos, Nigeria. The mission of WeBelieve Health is to increase access to quality care for Nigerians and to facilitate knowledge sharing to improve healthcare delivery. ${ }^{25}$ The objective of the symposium was to outline the current state of emergency medicine in Nigeria and to brainstorm strategies to improve emergency care delivery in the country. The researchers all conduct research in global health, and they are composed of emergency medicine physicians, a family medicine physician and a public health physician.

\section{Patient involvement}

There was no patient involvement in the design, conduct, reporting or dissemination plans of our research.

\section{Recruitment of participants}

Participants were made aware of our intention to conduct focus group discussions at the start of the symposium. Participation was voluntary and without restriction or incentive. A total of 66 symposium attendees, $43 \%$ of the total 152 symposium registrants, agreed to participate. Fifty-two participants were healthcare professionals, which included medical officers, surgeons, nurses and medics, and 14 were non-healthcare professionals, which included reporters, business professionals and policy makers (table 1). In order to ensure a random grouping of healthcare and non-healthcare, participants were divided by numbering off $1-7$ to form groups of $8-11$ people.

\section{Data collection and management}

We collaborated with the Department of Community Health and Primary Care at the University of Lagos College of Medicine and Lagos University Teaching Hospital (LUTH) to facilitate the seven focus group discussions. Facilitators from LUTH were only involved with data collection and not data management or analysis. Each group was led by two facilitators; one facilitator served as the moderator and the other facilitator served as the assistant. Moderators were experienced in qualitative data analysis and conducting focus groups. Assistants 
were community volunteers and were provided same-day training on the principles and processes of qualitative data collection and management. Each facilitator was fluent in English and pidgin English. The focus groups were conducted in English language.

Small group facilitators obtained verbal consent from each participant at the beginning of each focus group discussion. Facilitators used open-ended, semistructured questions predeveloped and included in an interview guide adopted from focus group scripts used in a Zambian pilot study ${ }^{26}$ (online supplemental file 1). The script was designed to capture participant opinions specifically about emergency care, making it an excellent template to use, with adaptation, in our study. The focus groups were audio-recorded with a digital voice recorder and transcribed verbatim in English by the facilitator assistant into Microsoft Word 13, V.15.0. NVivo V.12, a computerassisted qualitative data analysis software, was used to facilitate data management and organisation.

\section{Data analysis}

Using a team-based approach, we employed conventional content analysis to apply codes that emerged directly from the narrative data. Two research members coded independently by carefully exploring each transcript to ensure recognition of the most salient codes and patterns. The investigators then compared their applied codes and categorised the emerging codes into overarching themes using in vivo descriptors embedded directly in the text. Shared decision-making continued until group consensus was achieved. The investigators also conducted quality assessments of the results with the Standards for Reporting Qualitative Research (SRQR) checklist ${ }^{27}$ (online supplemental file 2).

\section{RESULTS}

The interview guide was developed to explore the participants' experiences and interactions with the emergency care system at the prehospital setting, the hospital setting and at the health system level. Participants further characterised their perceived challenges at each of these sectors as it relates to prehospital care delivery, hospital care delivery and health system governance. Challenges were classified by descriptive themes according to the most commonly used terms by the focus group participants. The descriptive themes were rudimentary, vulnerable and disconnected (table 2).

\section{Prehospital care delivery}

Participants acknowledged that emergencies are very common but that poor conditions and the absence of first aid supplies lead them to consider the prehospital system as rudimentary, which was a repeated descriptor for the undeveloped, or as participant 1 of focus group (FG) 1 and participant 6 of FG 5 stated 'non-existent', infrastructure currently in place to deliver care to patients at the scene of injury or illness. It also represented the community's understanding of basic life support interventions such as performing cardiopulmonary resuscitation (CPR). An overall impression was that effective and prioritised interventions in prehospital care delivery would result in the biggest impact to Nigeria's emergency care system.

\section{Emergency recognition and response}

The first step in emergency response is recognising the emergency. Participants generally defined an emergency as any condition that, if not provided urgent attention, will result in loss of life or long-lasting disability. Nearly all of the participants verbalised that they had personally witnessed an emergency, with many having witnessed an emergency on at least three separate occasions (table 3). Although many stated that they are willing to help a victim in need of emergency care, they lack training in providing basic life support, and the first aid equipment needed to facilitate care delivery is not readily available. Participant 6 from FG 6 mentioned a time when he witnessed a woman being hit by an okada (okada is a common motorcycle taxi in Nigeria). He did not offer help because he did not have a first aid kit, and therefore he did not feel empowered to provide care without medical supplies. For this reason, the participant mentioned that the majority of patients receive initial care by family members or bystanders who lack formal training.

\section{Ambulances and frontline providers}

There were disagreements related to the presence of a universal access number that individuals can call to report and request emergency help. Multiple numbers were identified as the universal emergency access number in Nigeria: 199, 112 and 122. The most recognised number was 122, although many discussed that it was unreliable. If successful in reaching an operator to dispatch emergency personnel, the next challenge is having the ambulance reach the patient in a timely manner. Many participants attributed delay in first responder arrival to poor roads and excessive traffic. Also reported as contributing to delayed ambulance arrival to the scene is that ambulances are generally not granted the right-of-way when travelling. Many of the medics reported an average of 1-2 hours to get to the scene of injury or illness, irrespective of where you live, and then an additional 1-2 hours to get to the nearest hospital. The result is that the vast majority of patients arrive at a healthcare facility by private vehicle, taxi service, public transit or by foot. Participant 1 from FG 4 recalled an incident when a pregnant woman was seen in a clinic and noted to have an elevated blood pressure. She was sent by public transportation to go to the hospital. Formal transportation was not arranged, and she had a seizure on the bus and died shortly thereafter, before reaching the hospital. Even when an ambulance does arrive at the scene, there is no standardised approach to the care of injured or ill patients. Medics are prehospital personnel who transport patients by ambulance to clinics or hospitals. Medics who were present 


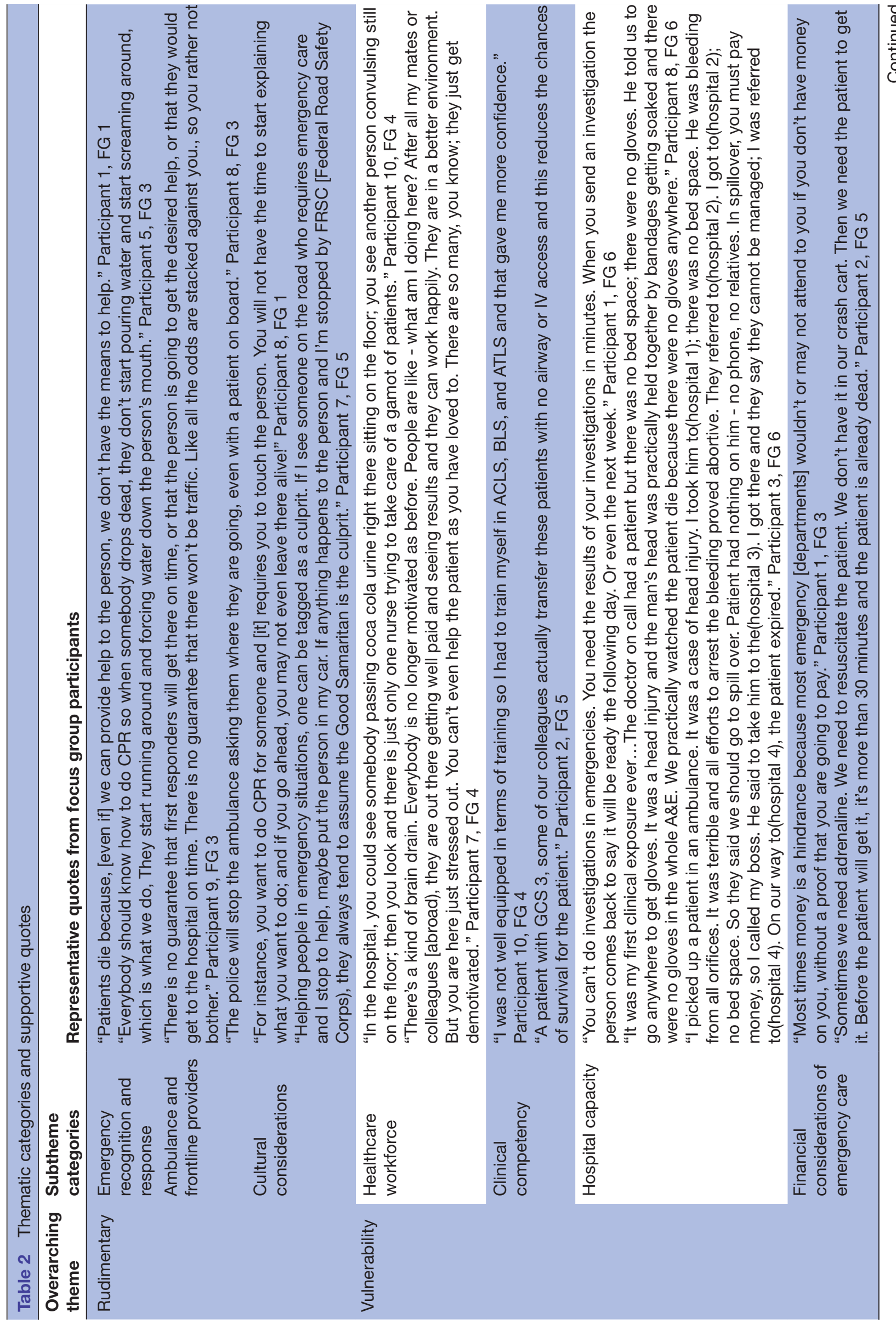


Table 3 Types of emergencies most commonly referenced Trauma Falls

Road traffic accidents

Mass casualty incidents

$\begin{array}{ll}\text { Medical } & \text { Asthma } \\ \text { Malaria } & \text { Stroke } \\ \text { Perforated peptic ulcer }\end{array}$

discussed their experience with feeling unsafe transferring patients, particularly trauma patients, who require well-coordinated patient handling to prevent cervical spine injury.

\section{Cultural considerations}

Many participants, primarily healthcare providers, described their fear of retribution for delivering care outside of the hospital environment due to weak Good Samaritan protections. One physician, participant 8 of FG 4 , recounted an experience of his colleague who was jailed for providing care to a patient and then transporting the patient in her private vehicle to the hospital. The patient ultimately succumbed to his injuries on arrival to the hospital, and the physician was arrested by the police while they investigated the cause of injury. Other healthcare providers echoed this experience providing their own stories of similar circumstances where either themselves or colleagues were subject to harassment for simply providing prehospital care. Participant 6 of FG 1 recalled an incident where a man in a rural part of Nigeria was performing CPR on a female patient who suddenly collapsed. The neighbours reported the man to the girl's father as trying to kiss and fondle the girl instead of trying to save her life.

\section{Hospital care delivery}

Participants discussed hospital care delivery, with vulnerability being a recurrent theme related to the workforce, clinical competency and hospital capacity. Many healthcare workers reflected on their sense of helplessness when caring for the ill and injured, while many laypersons dwelled on their fears of becoming ill or injured and being cared for in the current emergency care system. When surveyed on whether they would seek care in Nigeria versus abroad if they had the option, the vast majority answered abroad.

\section{Health workforce}

Healthcare workers in the groups shared clinical experiences with cases where alternative or less invasive interventions were not considered because of the lack of qualified personnel. An orthopaedic surgeon, participant 7 of FG 3 , recalled a patient who presented to the hospital after he was run over by a truck and suffered a crush injury to the leg. Because of the delay presenting to the hospital and the extent of injury to the leg, the decision was made 
to amputate and he was a part of the operative team. He discussed his regret that, had there been a qualified surgeon with the capabilities of vascular and small nerve reconstruction, the man's leg could have been saved.

Healthcare participants who worked in rural settings discussed their frustrations with the inequitable distribution of the healthcare workforce, stating that it is generally concentrated in major cities such as Lagos, Ibadan and Abuja. Many voiced that they felt overwhelmed and described many symptoms of burn out. Identified contributions to clinical exhaustion were poor training, inadequate skills acquisition, high patient-to-provider ratios, lack of security and insufficient administrative support. Many stories were told of incidents when patients and their families physically assaulted physicians because they disagree with their recommendations, are annoyed with long waiting times or are frustrated with care delivery. As participant 7 of FG 4 put it, morale and motivation is lacking.

\section{Clinical competency}

Many healthcare participants admitted to inadequate training in triage. Participant 6 of FG 6 shared an incident when a patient was found to be aggressive. To address this patient's aggression, they administered diazepam, which works as a sedative. When this did not work, they administered chlorpromazine, which is an antipsychotic. Once the patient calmed down, they searched her phone and called many contacts. Eventually they reached her sister, who informed the team that the patient was diabetic. Only then did the team check her blood sugar, revealing that it was dangerously low. With this new information, they began resuscitation with blood glucose and she eventually recovered, but the delay in glucose administration could have resulted in irreversible brain damage and even death.

\section{Hospital capacity}

Participants 7 and 11 of FG 2, who work in an emergency department, spoke about the difficulty of accepting patients due to the space limitations. For this reason, many patients are refused entry and referred to other hospitals. A general sentiment though among participants was that if you are privileged and know the right people, you can get around limited hospital capacity. As participant 2 of FG 4 shared, he had a relative who needed oxygen, but when they arrived at the hospital, there was no space. Fortunately, they knew the governor and called him. Moments later, the participant's relative was admitted.

An additional limitation to care delivery, as noted by participants, is the availability of medical equipment and supplies. Many scrutinised the baseline scarcity of basic personal protective equipment like gloves. Participant 5 of FG 6 mentioned that staff are encouraged to reuse gloves while at work and that if a patient wants the staff to change their gloves when caring for them, then the patient themselves would need to buy and supply the hospital staff with gloves. Participant 1 of FG 5 uses aprons or bed sheet linens to cover his hands in place of gloves. Further impediments related to laboratory and radiologic investigations also delay care. Healthcare providers mentioned that it may take days to get laboratory results back. Others discussed the difficulty obtaining radiographic studies such as X-rays, CT scans and MRI.

\section{Financial considerations of emergency care}

Participant 6 of FG 6 shared an intimate story of her relative who was in respiratory distress. They took him to three hospitals before he was accepted and provided with oxygen. But by this time, it was too late and he eventually died. He was turned away from the two nearest private hospitals because of the inability to pay. Participant 9 of FG 3 discussed the dichotomy experienced among Nigerians based on socioeconomic status. One woman, she recalled, had a minor motor vehicle accident but because of her financial status, she was immediately taken to the nearest hospital, admitted within minutes and tended to by various medical and surgical specialties. On the other hand, another man, involved in a traffic accident, arrived at the hospital unconscious, and care was delayed because he did not have money. After many calls to his family to secure funding, he was eventually cared for but unfortunately succumbed to his injuries. Participant 4 of FG 6 recalled an emotional story of a young child who fell on an iron rod which burned her abdominal wall to the point of exposing her viscera. She needed surgery but the family did not have the funds. The patient was admitted but waited many days until the medical students could raise funds to cover the procedure.

\section{Health system governance}

Nigeria's healthcare system is 'still in the pipeline' as participant 2 of FG 6 stated, resulting in disconnected coordination and collaboration among essential stakeholders, agencies and facilities relevant to emergency care delivery. The focus of health system challenges and solutions, among participants, centred on the functions of the central federal government and its responsibility in facilitating healthcare access and financing.

\section{Healthcare access and financing}

Many participants voiced their frustration that various components of the health system function in silos rather than in an integrated manner. An identified barrier to improvements in hospital care is the bureaucratic environment within the federal government and that there does not seem to be a centralised office or agency coordinating healthcare delivery at the national level to ensure equitable access at the state and local level. Participants discussed the current National Health Insurance Scheme (NHIS), which was meant to serve as a solution and provide financial insurance for those seeking healthcare services. ${ }^{28}$ An issue recognised by healthcare workers is that if a patient comes in with acute ailment, you have to first send a code to the NHIS before rendering care 
to receive pre-approval for care rendered. And until you receive approval, all care provided prior to a notification from the NHIS is not covered, which as participant 6 of FG 6 stated, negates its utilisation in emergency situations.

Many participants identified the unaffordable cost for medical care as the reason patients seek care with traditional or alternative healthcare providers. It is not until these remedies fail that many patients present to a clinic or hospital. For example, many patients cannot afford the cost of antiepileptic medications. Participant 5 of FG 3 described the common practice of burning the legs of a convulsing child. This practice is thought to rid the child of evil spirits causing the seizure. After this fails, the child is brought to a hospital, having now suffered complications of both seizures and burns. The overall impression of participants was that the aim of sustainable healthcare access and financing is to reduce and eventually eliminate health disparities, particularly those created by economic privilege.

\section{DISCUSSION}

The participants identified the rudimentary components of emergency response, prehospital infrastructure and community knowledge deficit of basic life support. The group provided examples of the vulnerabilities intrinsic to hospital care delivery such as an inadequate health workforce, deficient clinical competency for managing the acutely ill and injured, poor hospital capacity and multiple instances of delayed care because of poverty. Additionally, the participants revealed the disconnection between policies aimed at ensuring healthcare access and financing and the actual experiences of Nigerians who seek health services. Strengthening the Nigerian emergency care system will require implementing communityinformed interventions concertedly at the prehospital, hospital and health systems levels.

At the prehospital level, the majority of participants reported being able to recognise an emergency but there remains a knowledge deficit on how to appropriately intervene during an emergency. One suggested strategy to augment emergency care delivery is to train laypersons on basic life support, which has proven successful in many LMICs, including in sub-Saharan Africa. ${ }^{29}{ }^{30}$ Moreover, participants alluded that policy leaders should prioritise strengthening Good Samaritan laws so that well-intended bystanders are empowered to initiate basic life support and be protected while doing so. ${ }^{12}$

The findings from our discussions suggest modernising the prehospital infrastructure as well as the road traffic networks that integrate even the most remote communities. ${ }^{19}$ Solutions have been identified and proposed that are applicable to the Nigerian context. ${ }^{31}$ Local governments can start by investing in an adequate fleet of ambulances that are equipped with medical supplies, medications, oxygen and reliable communication systems. Drivers of these ambulances are recommended to be trained in an accredited education system and evaluated for competency with didactic and clinical assessments. Ambulances should also be strategically located to reach victims throughout a metropolitan region with centralised call centres in place to guide their response. Additionally, one national and universal emergency number should be recognised with toll-free calling accessible with all telecommunication services. ${ }^{32} 33$

Hospitals themselves face many challenges, as many Nigerians lack trust in available primary and secondary health facilities, bypassing them to seek care at even farther tertiary facilities. ${ }^{34}$ Wen et al reported on lower than expected utilisation of emergency departments within the Nigerian capital of Abuja despite similar location and layout of their emergency departments when compared with similar departments in the USA.$^{35}$ Focus group participants identified potential reasons being related to factors that are overwhelming the Nigerian workforce as well inadequate training in emergency care delivery. Strategic partnerships with established external organisations can help to build sustainable training programmes in emergency medicine ensuring clinical competency in the recognition, management and definitive treatment of patients suffering from acute illness or injury and have been successful in similar settings. ${ }^{36}$ Proper training in emergency and trauma resuscitation is essential to ensuring appropriate care delivery and improving patient outcomes and may encourage patients to appropriately use health services available to them locally. 1233

To improve access to care, participants mentioned categorising health facilities based on their capabilities so that patients and prehospital providers can seek care at the most suitable facility, which may support the appropriate allocation of limited resources. ${ }^{12}$ Another suggested approach involves partnering with religious and holistic entities to address social and cultural norms that deter individuals from seeking appropriate care in health facilities in a timely manner. ${ }^{37}$

Emergency care may involve extensive investigations to evaluate and diagnose high-risk injuries or illness which can be costly. But despite its costs, global consensus is that all people should have access to emergent health services without the fear of financial hardship. ${ }^{4}$ Some countries, like the USA, have enacted policies that require emergency care to be rendered irrespective of a patient's ability to pay. ${ }^{38}$ Nigeria has similar policies requiring care delivery regardless of one's ability to pay, but the policy does not translate to the experiences of individuals who proclaim that financial capabilities are a factor in the care they receive. ${ }^{28}$ This was a recurrent concern among participants. The National Health Act (NHA) was enacted in 2014 with the goal of improving healthcare financing and expanding care access, including emergency care, by establishing a Basic Healthcare Provision Fund (BHCPF). However, BHCPF was not actually included in the federal budget until 2018. ${ }^{39} 40$

According to the World Bank, of the $\$ 74$ per capita spent on health expenditures in Nigeria, $77 \%$ is paid 
out-of-pocket. ${ }^{41}{ }^{42}$ This is in comparison to aggregate data revealing that globally only $18 \%$ of health expenditures are paid out-of-pocket. ${ }^{43}$ A general sentiment among participants was for more efforts to be taken to ensure that the BHCPF is providing citizens with access to basic primary and emergency care, as well as universal health coverage. Nigeria's ability to successfully implement the promises of the NHA could catapult the nation to be on track with international standards for healthcare access and quality.

\section{Limitations}

Study limitations should be considered. The focus groups were conducted among participants of an emergency medicine symposium and therefore captured individuals actively engaged or interested in emergency care service delivery, many of whom are healthcare providers, who have pre-existing knowledge and intimate experience with the healthcare system, which may have impacted the themes and concerns that they expressed in the focus groups. The participants also attended conference sessions prior to participating in the study, which may have biased their perceptions and influenced the discussions. The study captured a small sample size because it was limited to the participants of a symposium, and therefore, the themes that emerged may be biased towards the cohort of individuals present. And lastly, by nature of design, our study highlights the perceptions of symposium participants but recognises that their opinions and claimed experiences are subject to recall bias and cannot be verified.

\section{CONCLUSION}

The participants in our study identified shortcomings in the Nigerian emergency care system. Participants were able to outline challenges and opportunities characterising prehospital care delivery, hospital care delivery and health system governance. Themes also emerged to describe the components of the emergency care system as rudimentary, vulnerable and disconnected, respectively. The results of this study may help healthcare professionals, policy makers and community leaders identify gaps in the emergency care system and offer solutions in harmony with the needs, values and expectations of the community. If successful, these community-informed interventions may serve as a model to improve emergency care systems throughout Africa.

\section{Author affiliations}

'Department of Emergency Medicine, Johns Hopkins University School of Medicine, Baltimore, Maryland, USA

${ }^{2}$ Department of Emergency Medicine, Howard County General Hospital, Columbia, Maryland, USA

${ }^{3}$ Department of Communicable and Non-Communicable Disease (CND) Cluster of the Country Office, World Health Organization Regional Office for Africa, Abuja, Federal Capital Territory, Nigeria

${ }^{4}$ Department of Emergency Medicine, Brigham and Women's Hospital, Boston, Massachusetts, USA

${ }^{5}$ Department of Family Medicine, Lagos University Teaching Hospital, Idi-Araba, Lagos, Nigeria
${ }^{6}$ Department of Emergency Medicine, Beth Israel Deaconess Medical Center, Boston, Massachusetts, USA

\section{Twitter Agnes Usoro @aausoro}

Contributors Conception and design of the study: All authors. Acquisition, analysis and interpretation of data: $\mathrm{AU}, \mathrm{BA}, \mathrm{BAA}, \mathrm{AO}$. Drafting the manuscript: $\mathrm{AU}, \mathrm{AO}$. Critical revisions to manuscript for intellectual content: AU, JS, SK. Supervision and final approval of manuscript version for publication: BAA, AO. AU and AO take responsibility for the manuscript as a whole.

Funding This research was supported by the Shore's Grant at Beth Israel Deaconess Medical Center, Boston, Massachusetts, USA.

Competing interests None declared.

Patient consent for publication Not required.

Ethics approval The Institutional Review Board (IRB) at the Lagos University Teaching Hospital and at Beth Israel Deaconess Medical Center provided ethical approval for this study.

Provenance and peer review Not commissioned; externally peer reviewed.

Data availability statement All data relevant to the study are included in the article or uploaded as supplemental information.

Supplemental material This content has been supplied by the author(s). It has not been vetted by BMJ Publishing Group Limited (BMJ) and may not have been peer-reviewed. Any opinions or recommendations discussed are solely those of the author(s) and are not endorsed by BMJ. BMJ disclaims all liability and responsibility arising from any reliance placed on the content. Where the content includes any translated material, BMJ does not warrant the accuracy and reliability of the translations (including but not limited to local regulations, clinical guidelines, terminology, drug names and drug dosages), and is not responsible for any error and/or omissions arising from translation and adaptation or otherwise.

Open access This is an open access article distributed in accordance with the Creative Commons Attribution Non Commercial (CC BY-NC 4.0) license, which permits others to distribute, remix, adapt, build upon this work non-commercially, and license their derivative works on different terms, provided the original work is properly cited, appropriate credit is given, any changes made indicated, and the use is non-commercial. See: http://creativecommons.org/licenses/by-nc/4.0/.

ORCID iDs

Agnes Usoro http://orcid.org/0000-0002-0010-0277

Benjamin Aiwonodagbon http://orcid.org/0000-0002-1717-8206

Jonathan Strong http://orcid.org/0000-0002-6299-8297

Sean Kivlehan http://orcid.org/0000-0002-4857-4316

Babatunde A Akodu http://orcid.org/0000-0002-0989-3568

Ayobami Olufadeji http://orcid.org/0000-0003-4891-7291

\section{REFERENCES}

1 World Health Organization. Seventy-second World health assembly. resolution WHA72.16: emergency care systems for universal health coverage: ensuring timely care for the acutely ill and injured. Geneva, 2019.

2 Razzak JA, Kellermann AL. Emergency medical care in developing countries: is it worthwhile? Bull World Health Organ 2002;80:900-5.

3 Macfarlane S, Racelis M, Muli-Musiime F. Public health in developing countries. Lancet 2000;356:841-6.

4 World Health Organization. Universal health coverage, January 2019. Available: https://www.who.int/news-room/fact-sheets/detail/ universal-health-coverage-(uhc) [Accessed Apr 2020].

5 Downie R. Promoting accountability in Nigeria's health system. Center for Strategic and International Studies Global Health Policy Center, February 2017. Available: https://csis-prod.s3.amazonaws. com/s3fs-public/publication/170221_Downie_PromotingAccount abilityNigeria_Web.pdf?87Nrn7MgZAoMhwhj6jcfzbZPKWYtkaJd [Accessed May 2020].

6 Nigeria GDP 1960-2020. Macrotrends. Available: https://www. macrotrends.net/countries/NGA/nigeria/gdp-gross-domestic-product [Accessed Nov 2020].

7 GBD 2016 Healthcare Access and Quality Collaborators, Fullman N, Yearwood $\mathrm{J}$, et al. Measuring performance on the healthcare access and quality index for 195 countries and territories and selected subnational locations: a systematic analysis from the global burden of disease study 2016. Lancet 2018;391:2236-71. 
8 Karan A, DeUgarte D, Barry M. Medical "Brain Drain" and Health Care Worker Shortages: How Should International Training Programs Respond? AMA J Ethics 2016;18:665-75.

9 Welcome MO. The Nigerian health care system: need for integrating adequate medical intelligence and surveillance systems. J Pharm Bioallied Sci 2011;3:470-8.

10 The world bank. Hospital beds (per 1,000 people) - Nigeria. Available: data.worldbank.org/indicator/SH.MED.BEDS.ZS?most_ recent_value_desc=false [Accessed April 25, 2020]

11 Pharmaccess.org. A closer look at the healthcare system in Nigeria, 2016. Available: www.pharmaccess.org/wp-content/uploads/2018/ 01/The-healthcare-system-in-Nigeria.pdf [Accessed April 2020].

12 Reynolds T, Sawe H, Rubiano A, et al. Strengthening health systems to provide emergency care. In: Disease control priorities. 9. 3rd edn. Washington, DC: The World Bank, 2018.

13 The World Bank. Population, total - Nigeria. Available: https://data. worldbank.org/indicator/SP.POP.TOTL?locations=NG [Accessed 15 Nov 2020].

14 The World Bank. Death rate, crude (per 1,000 people) - Nigeria. Available: https://data.worldbank.org/indicator/SP.DYN.CDRT.IN? locations=NG [Accessed 15 Nov 2020].

15 Ugare GU, Bassey IE, Udosen JE, et al. Trauma death in a resource constrained setting: mechanisms and contributory factors, the result of analysing 147 cases. Niger J Clin Pract 2014;17:397-402.

16 National Postgraduate Medical College of Nigeria. Residency training program accredited institution database, 2020. Available: https:// npmcn.edu.ng/residency-training-program-accredited-institutiondatabase/

17 Obermeyer Z, Abujaber S, Makar M, et al. Emergency care in 59 lowand middle-income countries: a systematic review. Bull World Health Organ 2015:93:577-86.

18 Adewole OA, Fadeyibi IO, Kayode MO, et al. Ambulance services of Lagos state, Nigeria: a six-year (2001-2006) audit. West Afr J Med 2012;31:3-7.

19 Cannoodt L, Mock C, Bucagu M. Identifying barriers to emergency care services. Int J Health Plann Manage 2012;27:e104-20.

20 Nnamdi N. Improving Care \& Response in Nigeria. J Emerg Med Serv 2017;6.

21 DaCosta A, Osonuga A, Adesegun O. The urgent need for postgraduate medical training in emergency medicine in Nigeria. Afr J Emerg Med 2020;10:1-2.

22 Mac PA, Kroeger A, Airiohuodion PE. Needs assessment of emergency medical and rescue services in Abuja/Nigeria and environs. BMC Emerg Med 2019;19:78

23 Rabiee F. Focus-group interview and data analysis. Proc Nutr Soc 2004;63:655-60.

24 Yin RK. Qualitative research from start to finish. 2 edn. New York, London: Guilford Press, 2016.

25 webelievehealth. Available: https://www.webelievehealth.com/ [Accessed 15 Nov 2020].

26 Broccoli MC, Cunningham C, Twomey M, et al. CommunityBased perceptions of emergency care in Zambian communities lacking formalised emergency medicine systems. Emerg Med $J$ 2016;33:870-5

27 O'Brien BC, Harris IB, Beckman TJ, et al. Standards for reporting qualitative research: a synthesis of recommendations. Acad Med 2014;89:1245-51.

28 Federation of Nigeria. National health act, 2014. The federal Republic of Nigeria official Gazette. Vol 101, No 145, 2014.
29 Mock CN, Quansah R, Addae-Mensah L, et al. The development of continuing education for trauma care in an African nation. Injury 2005;36:725-32.

30 Jayaraman S, Mabweijano JR, Lipnick MS, et al. Current patterns of prehospital trauma care in Kampala, Uganda and the feasibility of a lay-first-responder training program. World J Surg 2009;33:2512-21.

31 Kobusingye OC, Hyder AA, Bishai D, et al. Emergency medical systems in low- and middle-income countries: recommendations for action. Bull World Health Organ 2005;83:626-31.

32 Suryanto S, Plummer V, Boyle MJ. Ems systems in Lower-Middle income countries: a literature review. Prehosp Disaster Med 2016;32:1.

33 Thind A, Hsia R, et al, The International Bank for Reconstruction and Development / The World Bank. Prehospital and Emergency Care. In: Debas HT, Donkor P, Gawande A, eds. Essential surgery: disease control priorities. (Volume 1). 3 Edn. Washington (DC, 02 Apr 2015.

34 Nigerian Federal Ministry of Health. National health policy 2016: promoting the health of Nigerians to accelerate socioeconomic development, 2016. Available: https://extranet.who.int/countryplann ingcycles/sites/default/files/planning_cycle_repository/nigeria/draft nigeria_national_health_policy_final_december_fmoh_edited.pdf [Accessed 11 May 2020].

35 Wen LS, Oshiomogho Jl, Eluwa Gl, et al. Characteristics and capabilities of emergency departments in Abuja, Nigeria. Emerg Med $J$ 2012;29:798-801. Epub.

36 Rybarczyk MM, Ludmer N, Broccoli MC, et al. Emergency medicine training programs in low- and middle-income countries: a systematic review. Ann Glob Health 2020;86:60.

37 Onuminya JE. Performance of a trained traditional bonesetter in primary fracture care. S Afr Med J 2006;96:320-2.

38 Emergency Medical Treatment and Labor Act. United States Code. Chapter 7 - Social security. Subchapter XVIII - Health insurance for aged and disabled. Part E - Miscellaneous provisions. Section 1395dd - Examination and treatment for emergency medical conditions and women in labor. January Edition, Supplement 4. In: Title 42 - The Public Health and Welfare. 2011, 2006. https://www. govinfo.gov/app/details/USCODE-2010-title42/USCODE-2010title42-chap7-subchapXVIII-partE-sec1395dd/summary

39 Richard D. Promoting accountability in Nigeria's health system, February 2017. Center for strategic and international studies global health policy center. Available: https://csis-prod.s3.amazonaws.com/ s3fs-public/publication/170221_Downie_PromotingAccountabilityN igeria_Web.pdf?87Nrn7MgZAoMhwhj6jcfzbZPKWYtkaJd [Accessed May 2020].

40 Global Financing Facility. Case study Nigeria. The mission to provide the National health act with adequate funding. Available: https:// www.globalfinancingfacility.org/sites/gff_new/GFF-Annual-report/ nigeria.html [Accessed May 2020].

41 The World Bank. Current health expenditure per capita (current US\$) - Nigeria, November 14, 2020. Available: https://data.worldbank.org/ indicator/SH.XPD.CHEX.PC.CD?end=2017\&locations=NG\&start= 2015

42 World Health Organization. Health expenditures profile Nigeria. Available: https://apps.who.int/nha/database/country_profile/Index/ en [Accessed 14 Nov 2020].

43 The World Bank. Out-Of-Pocket expenditure (\% of current health expenditure) - world. Available: https://data.worldbank.org/indicator/ SH.XPD.OOPC.CH.ZS [Accessed 14 Nov 2020]. 